\title{
LA GÜERA RODRÍGUEZ: LA CONSTRUCCIÓN DE UNA LEYENDA ${ }^{1}$
}

\author{
Silvia Marina Arrom \\ Brandeis University
}

\begin{abstract}
N aría Ignacia Rodríguez de Velasco y Osorio (1778-1850), 1 conocida simplemente como “la Güera Rodríguez”. La mujer preciosa y simpática que dicen que cautivó a Simón Bolívar, Alexander von Humboldt y Agustín de Iturbide, y que ayudó al movimiento independentista. El personaje que me fascinó desde que hace 50 años leí Life in Mexico (1843), el relato de Fanny Calderón de la Barca, la esposa del ministro español, en 1840 y 1841 , quien se hizo su buena amiga y nos cuenta que Humboldt la había pronunciado la mujer más bella que jamás había visto. ${ }^{2}$ Después leí La Güera Rodríguez de Artemio
\end{abstract}

Fecha de recepción: 5 de noviembre de 2018

Fecha de aceptación: 9 de enero de 2019

\footnotetext{
${ }^{1}$ Versiones preliminares de este artículo fueron presentadas en tres seminarios: el Boston Area Workshop on Latin American and Caribbean History (Harvard University, febrero de 2017), el Latin American Historians of Northern California (Berkeley CA, diciembre de 2017) y el Seminario Permanente de Historia Social, México, El Colegio de México, Universidad Nacional Autónoma de México, febrero de 2018). Le agradezco al público de esas presentaciones sus comentarios.

${ }^{2}$ Calderón de la Barca, Life in Mexico, especialmente p. 141.
} 
de Valle-Arizpe (1949), que pinta un cuadro inolvidable de "una de las figuras más brillantes" de la historia de México. ${ }^{3} \mathrm{Y}$ cuando, hace ya 40 años, encontré varios documentos sobre ella en los archivos, publiqué una selección del largo juicio de divorcio eclesiástico que siguió con su primer marido y guardé mis notas para algún uso futuro. ${ }^{4}$

Por eso cuando decidí escribir su biografía sentí que volvía a visitar a una antigua amiga. Pero al examinar lo que se había escrito sobre ella desde entonces, apenas la reconocí. Ha sido sujeto de una obra teatral (1955), película (1977), ópera (1982), historieta (1990) y novela (2005) -entre otros textos- ${ }^{5}$ Su fama estalló durante el bicentenario de la independencia con reposiciones y reimpresiones de esas obras, así como con nuevas representaciones en publicaciones populares, programas de televisión y blogs. Al seguir su ascenso de la relativa oscuridad a la fama, la vi cambiar ante mis ojos. De un papel secundario en el movimiento independentista pasó a ser una de sus principales protagonistas. En el siglo xx no hubo una sola estatua, calle o escuela con su nombre, el reconocimiento oficial que ha tocado a tantas heroínas. En cambio, en 2010, los carteles que anunciaban la comedia y la ópera La Güera Rodríguez estaban por toda la ciudad de México, y cuando su glamorosa imagen apareció en un alebrije conmemorando el bicentenario, se le reconocía de

3 Valle-Arizpe, La Güera Rodríguez, cita del prólogo titulado "Isagoge". 4 "Don José Villamil y Primo contra María Ignacia Rodríguez, 1802”, en Arrom, La mujer mexicana, pp. 63-107.

${ }^{5}$ Comedia de Federico Schroeder Inclán, Hoy invita la Güera; película de Felipe Cazals, La Güera Rodríguez, FUNAM; ópera de Carlos Jiménez Mabarak, La Güera Rodríguez, véase SosA, Diccionario, pp. 189-196; historieta de Bastien y Plaza, “La Güera Rodríguez”; novela de Arrioja Vizcaíno, El águila en la alcoba. Todavía no se ha publicado una biografía seria de doña María Ignacia Rodríguez. César Alejandro Martínez Núñez empezó esa tarea en su tesis inédita que contiene valiosas referencias documentales, aunque no logra desprenderse de algunos mitos: "Biografía crítica". 
inmediato como una de las amadas patriotas mexicanas. ${ }^{6} \mathrm{El}$ Museo de la Mujer, inaugurado en 2011, la ubicó como una de apenas cuatro mujeres en la sala Las Mujeres Insurgentes. ${ }^{7} \mathrm{Y}$ diversos autores hicieron afirmaciones cada vez más exageradas: "la primera mujer en México que, sin ser electa, ejerció poder político", "la heroína fundamental de la independencia de México, muy por encima de doña Josefa Ortiz de Domínguez o de doña Leona Vicario", "Es muy probable que sin ella no se habría consumado la independencia”, y "La Madre de la Patria". 8 A la vez, se transformó de una intachable dama aristocrática a una mujer sexualmente liberada quien supuestamente tuvo numerosos amantes. Le atribuyeron relaciones ilícitas con Bolívar, Humboldt e Iturbide, entre muchos otros. La calificaron como "adicta al sexo", una "Marylín Monroe en su momento", y hasta una de "las 10 prostitutas más famosas de la historia”. 9

${ }^{6}$ La comedia y la ópera fueron reposiciones de las obras de 1955 y 1982 . Sobre el alebrije, véase el blog “The Amazing Adventures of los von ZauRunyon!”, 17 de octubre de 2010, http://vonzaurunyon.blogspot.com/2010 1017_archive.html, consultado el 3 de febrero de 2015.

7 Además de la Güera estaban Leona Vicario, Josefa Ortiz de Domínguez y Mariana Rodríguez del Toro de Lazarín. El catálogo de la exhibición añade una quinta heroína: Gertrudis Bocanegra. Galeana, Museo de la mujer, pp. 65-75. 8 Rodrigo Velázquez Moreno, "La Güera Rodríguez (1778-1850)", blog del 12 de febrero de 2014, http://algarabia.com/quien-fue/la-guera-rodriguez-1778-1850/?; El Mundo Según Yorch, "La Güera Rodríguez: heroína olvidada", blog del 20 de septiembre de 2010", http://elmundosegunyorch. blogspot.com/2010/09/la-guera-rodriguez-heroina-olvidada.html; Ana Díaz, "La Güera Rodríguez: La mujer detrás de la independencia”, blog del 8 de enero de 2013, https://www.belelu.com/2013/01/la-guera-rodriguezla-mujer-detras-de-la-independencia-de-mexico/, los tres consultados el 3 de febrero de 2015; y Garci, sección sobre "La Madre de la Patria”, en Más pendejadas, pp. 14-18.

9 El Mundo Según Yorch; Nicoletta Reznik, “¿Quién fue la Güera Rodríguez?” blog del 6 de agosto de 2011, http://lamaquinadelaverdad.blogspot. com/2011_08_06_archive.html; y www.wradio.com.co/multimedia/fotogalerias/conozca-a-las-10-prostitutas-mas-famosas-de-la-historia/20131106/ fotogaleria/2009008.aspx, consultados el 3 de febrero de 2015. 
Entonces comprendí que las representaciones de la Güera Rodríguez en los casi 170 años desde su muerte son en sí un tema digno de estudio. De hecho, ella ha sido sujeto de tantos mitos que es muy difícil desenredar a la mujer de la leyenda. Al tratar de hacerlo, descubrí que mucho de lo que yo creía saber sobre ella era ficción. Observé que una vez que aparecía una nueva historia, después se repetía como cierta. Y también que en diferentes periodos adquiría distintas identidades según cambiaban los valores y objetivos de los narradores. Así, el foco de mi investigación pasó del intento de escribir su biografía definitiva (de todas formas, imposible por las enormes lagunas en la documentación) al análisis de las muchas versiones de esta figura que ha merecido calificativos tan dispares como "magnífica”, "extraordinaria”, “astuta”, “pícara”, “seductora”, “libertina”, “ninfómana” y “feminista”. El examen de lo que podríamos llamar su "vida póstuma" nos ayuda a entender la cultura mexicana en varias épocas, porque cada texto refleja la ideología de su autor y el contexto de su época.

Por lo tanto, este estudio traza algunos momentos clave en su trayectoria por las artes y letras mexicanas -no en la historia oficial, en la que casi no aparece, sino en la cultura popular-. Sus constantes transformaciones nos recuerdan que hay una gran brecha entre los acontecimientos históricos y la memoria de éstos. El examen de la construcción de su leyenda ha adquirido una importancia adicional en una época de noticias falsas en que se inventan hechos para contar historias interesantes, porque eso fue precisamente lo que ocurrió con María Ignacia Rodríguez en su camino hacia convertirse en un ícono de la historia de México.

\section{LA “VERDADERA” DOÑA MARÍA IGNACIA RODRÍGUEZ}

Un breve resumen de la vida de doña María Ignacia Rodríguez nos ayuda a distinguir entre los mitos y los hechos 
comprobables. Hay mucho que no podemos conocer, sobre todo porque no se han encontrado sus cartas ni otros papeles personales que revelen sus pensamientos íntimos. No obstante, la abundante información en los registros públicos y crónicas contemporáneas ilumina muchos aspectos de su vida. Muestran una mujer de alta sociedad convencional, esposa maltratada, viuda desvalida, trepadora social, devota madre y católica piadosa, por mencionar sólo algunas de sus posibles identidades. Pero no apoyan sus representaciones posteriores como liviana seductora o rebelde desafiante, e indican que su papel en el movimiento por la independencia ha sido sumamente exagerado.

Sabemos que venía de una familia ilustre; su padre, un regidor perpetuo de la ciudad de México, y su madre, hija de un mayorazgo. Se movían en el cómodo mundo de la élite mexicana, donde las familias vivían cerca, se reunían con frecuencia, asistían a la iglesia regularmente y gozaban de una rica vida social. Y, aunque tenemos poca información sobre su infancia, la Güera debe haber recibido alguna instrucción formal porque leía y escribía con mano segura.

Lo que la distinguía de otras mujeres de su círculo social era su belleza y personalidad vivaz, rasgos señalados por dos viajeros de la época. Poco después de llegar a México en 1831, el conde francés Mathieu de Fossey vio a "la blonde Rodríguez" -"la mujer más aristocrática que conocí en México"- en una fiesta, rodeada de admiradores que se reían de sus cuentos divertidos. ${ }^{10}$ En 1840 Fanny Calderón la describe como muy simpática y todavía hermosa a pesar de tener 61 años. Y debe haber sido sumamente atractiva, pues se casó tres veces -la última vez, en 1825, con un señor 12 años menor que ella. ${ }^{11}$ Según Fanny, era

10 Fossey llegó a México en 1831 y dice que conoció a la Güera antes de la epidemia de cólera de 1833. Fossey, Le Mexique, p. 282.

${ }_{11}$ Por ser inusual la diferencia en sus edades, ella dio su edad como de 42 en vez de 46 en el acta matrimonial (5 de septiembre de 1825), FS, "México matrimonios, 1570-1959", FHL microfilm 206,005. 
un personaje conocido en la ciudad de México, siempre llamada por su apodo familiar y no sus nombres de pila. ${ }^{12}$ De hecho he encontrado ese apodo ya en 1812, y sus hijas con frecuencia eran identificadas como "las hijas de la Güera". ${ }^{13}$

La Güera fue sujeto de muchos chismes, sobre todo por los escandalosos pleitos que siguió con su primer marido, el capitán José Jerónimo Villamil -futuro heredero de un mayorazgo pero con pocos ingresos aparte de su salario como subdelegado de Tacuba-. Ella tenía 15 años al casarse, y en los 11 años que duró el matrimonio tuvieron seis hijos, de los cuales uno murió en la infancia. ${ }^{14}$ La unión fue bastante tormentosa debido a los celos de Villamil. En 1801 la acusó de adulterio con un francés, y a los diez días retiró la acusación. Entonces, el 4 de julio de 1802, le disparó su pistola en un arrebato de furia. Aunque el arma falló (más tarde él dijo que sólo había querido asustarla) la joven huyó de su casa en Tacuba a la de sus padres en la capital, donde demandó a su marido por intento de asesinato. Villamil fue puesto en arresto domiciliario y liberado bajo fianza el 29 de agosto. De inmediato -y aparentemente como venganzapresentó una demanda de divorcio eclesiástico (una separación, pues todavía no existía el divorcio absoluto) en la que acusaba a su mujer de "adulterio sacrílego" con tres curas distinguidos, entre ellos su propio compadre, el canónigo José Mariano

12 Calderón de la Barca, Life in Mexico, p. 142.

13 Véase, por ejemplo, la carta escrita en 1812 por la Marquesa de Villahermosa (y Condesa de Regla) a la exvirreina Inés de Jáuregui, en la que identifica a su nuera Josefa como "hija de la Güera". Citada en Romero de Terreros, ExAntiquis, p. 234.

${ }^{14}$ Los hijos del primer matrimonio fueron Josefa (1795), Antonia (1797), Jerónimo (1798), Agustín (1800, muerto en la infancia), Guadalupe (1801), y Paz (1805), FS, "México Bautismos, 1650-1950” y "México, Distrito Federal, registros parroquiales y diocesanos, 1714-1970"; y FN, https://gw.geneanet. org/sanchiz?lang=es\&p=antonia\&n=villar+villamil+rodriguez+de+velasco. 
Beristáin, autor de la famosa Biblioteca hispano-americana septentrional. ${ }^{15}$

De aquí nacen los primeros rumores de los adulterios de la Güera. Pero en los largos autos el marido no pudo probar nada, y la evidencia más bien sugiere que ella fue una esposa sufrida y maltratada. De hecho, los parientes, amigos y colegas de Villamil tomaron partido por su esposa, quien afirmaban ser la inocente víctima de su carácter volátil y violento -y algunos hasta la habían encontrado "bañada en sangre" por las golpizas que él le daba-. Después de cuatro meses Villamil desistió en su demanda. En algún momento la pareja se reunió y el 12 de junio de 1805 nació su última hija. Pero el matrimonio había terminado pocos meses antes con la muerte del capitán.

Viuda a los 27 años, con cinco hijos para criar sola, la Güera volvió a la ciudad de México, donde vivía su familia. Sufría escasez de dinero porque en lugar de gananciales Villamil había dejado deudas, su dote se había consumido durante el matrimonio, y las propiedades que serían de su hijo (y que ella administraba como su tutora y curadora durante su minoría de edad) no se podían vender por estar vinculadas. ${ }^{16}$ En menos de dos años, el 10 de febrero de 1807, se casó con el doctor Juan Ignacio Briones, un señor acaudalado que murió a los seis meses de la boda dejándola con su séptimo embarazo y una buena herencia. ${ }^{17}$

15 Los otros dos eran el canónigo provisto de Guadalajara, Ramón Cardeña y Gallardo, y el presbítero de México Ignacio Ramírez. Para una selección de cientos de páginas de documentos judiciales, véase Arrom, La mujer mexicana, pp. 63-107.

16 Sin embargo, no se quedó sin recursos, porque le asignaron 4000 pesos anuales del fondo del mayorazgo para su manutención y la de sus hijas, y otros 2000 para su hijo, el futuro heredero. Véase "Testamento de María Ignacia Rodríguez” (1 de abril de 1819), y “Testamento de María Ignacia Rodríguez” (16 de agosto de 1850), AHN, Francisco de Madariaga \#426, vol. 2830, f. 114v. y vol. 2873 , f. $597 \mathrm{v}$.

17 La herencia se valuó en 320000 pesos en 1811. AHN, Francisco de Madariaga \#426, vol. 2838 (1827), ff. 27v.-28; y “Testamento” (1819), vol. 2830, ff. 
Aunque La Güera enfrentó los 17 años de su segunda viudez con determinación, no puede haber sido fácil. En varios documentos ella se describe como "esta viuda desgraciada" con "cinco hijos inocentes, pequeñitos y sin padre". ${ }^{18}$ Su vida estaba marcada por la muerte y la enfermedad. La hija póstuma de Briones murió al año y medio, en 1808, y su hija Guadalupe murió a los 15 años, en 1816. Según su tía, la niña “inocente” había estado enfermiza por once años. Esto parece haber sido bastante traumático para la madre, quien menciona a su hija "moribunda” en varias ocasiones entre 1810 y 1816. Por ejemplo, en un litigio con su hermana sobre el alquiler de una casa explica que había descuidado sus asuntos por "hallarse trastornada con el grave cuidado de una hija que se le estaba muriendo". ${ }^{19}$ Y la Güera misma sufrió varias enfermedades serias: un certificado médico de marzo de 1810 describe síntomas que apuntan a una tuberculosis (e. g. tos sangrienta, hemorragias nasales, etc.) y en 1819 sufrió de nuevo una crisis tan extrema que dictó su testamento desde el lecho donde esperaba la muerte. ${ }^{20}$

114v.-115. Sobre Briones véase APA, Matrimonios de Españoles, libro 40, \#34, f. 10v. (10 de febrero de 1807) y Entierros de Españoles, libro 36, f. 107v. (16 de agosto de 1807). Sobre el nacimiento de su hija Victoria, véase FS, "México, Distrito Federal, registros parroquiales y diocesanos, 1514-1970" (22 de abril de 1808), FHL Microfilm \#35195.

18 Cartas de María Ignacia Rodríguez al virrey, 17 de marzo y 14 de abril de 1810, en "Averiguación que hace Bernardo de Prado, Inquisidor decano, contra María Ignacia Rodríguez de Velasco, sobre un atentado al virrey de la Nueva España” (1809-10), AGN, IC, IV, c. 4452, exp. 1, ff. 100 y 108.

19 "La Marquesa viuda de Uluapa contra doña María Ignacia Rodríguez su hermana” (1816-18), AGN, VM, vol. 225, exp. 1, esp. ff. 15, 17 y resumen del caso en 26 de septiembre, 1817. También véase la carta de María Ignacia Rodríguez al virrey (28 de abril de 1810), en "Averiguación”, AGN, IC, IV, c. 4452, exp. 1, f. 106; y carta de María a Rafael Vega (ca. 1814), en GuedeA (comp.), Prontuario, p. 364.

20 Certificado médico que acompaña su petición al virrey pidiendo se le levante el destierro (14 de abril de 1810), "Averiguación," AGN, IC, $I V$, c. 4452, 
A pesar del amplio legado de su segundo marido, parece que su situación financiera no era del todo sólida porque algunas de sus propiedades estaban hipotecadas y no siempre producían ganancias. Los rebeldes ocuparon sus valiosas haciendas San Isidro y Santa María en Guanajuato y las dejaron en la "ruina". También ocuparon (y dañaron) un rancho cerca del pueblo de Dolores y otro en Monterrey que formaban parte del patrimonio del hijo. Y para 1817 los ingresos de su hacienda de la Patera se habían esfumado. Después estas fincas sufrieron la severa deflación en el valor de la propiedad que acompañó a la independencia y perduró por varias décadas. De hecho, cuando trató de vender San Isidro, en 1826, había bajado tanto el precio que prefirió regalarla para pagar una deuda que le debía a parientes de su segundo esposo. ${ }^{21}$ Pero hizo lo que pudo para recuperarse, ayudada por sus excelentes conexiones con personas importantes de la época. Por ejemplo, en 1817 firmó un contrato con el capitán Domingo Malo, quien tomó la administración de varias de sus fincas y arrendó el Molino Prieto del mayorazgo de Villamil por 4600 pesos anuales; el fiador fue nada menos que su primo, Agustín de Iturbide. Claro que cuando cayó el Imperio y Malo suspendió los pagos, la fianza no valió nada por el exilio de Iturbide. ${ }^{22}$

Durante esta época la Güera se dedicó a la educación de sus cuatro hijos sanos -y parece haberlo hecho con mucho éxito-. Sus tres hijas asistieron al prestigioso colegio de La Enseñanza (la mejor escuela para niñas en la Nueva España) y se casaron

exp. 1, ff. 103-104; y “Testamento” (1819), AHN, Francisco de Madariaga \#426, vol. 2830, f. 113v.

${ }^{21}$ AGN, VM, vol. 215, exp. 10 (1818), en especial ff. 5 y 115v.; y AHN, Francisco de Madariaga \#426, vol. 2830 (1819), f. 115v.; vol. 2838 (1827), ff. 26v.-31; vol. 2840 (1829), ff. 482-486v.; vol. 2848 (1835), ff. 479-484v., y vol. 2852 (1837), ff. 191v.-194.

22 AHN, Francisco de Madariaga (\#426), vol. 2830 (1819), ff. 115v.-116 y vol. 2834 (1823), ff. 208v.-213. 
con hombres ricos, uno conde y los otros dos marqueses. ${ }^{23}$ Por lo tanto, consiguieron títulos de nobleza, algo que ella misma nunca pudo alcanzar. Y parece que lo anhelaba: el 6 de junio de 1809 le dio su poder al canónigo Ramón Cardeña para que la representara ante la corte española para pedir que el rey le concediera a ella y a su hijo "todos los honores, puestos y mercedes que sean de su Soberano agrado". ${ }^{24}$ Aunque nada resultó de este intento de avanzar la posición de la familia, Jerónimo prosperó: sucedió al abuelo materno como regidor, heredó el mayorazgo de su padre y sirvió en la Cámara de Diputados republicana. ${ }^{25}$ Tanto él como su hermana Antonia sobrevivieron a la madre, pero Josefa y Paz murieron con dos meses de diferencia en 1828, a los 32 y 23 años respectivamente. Entonces la Güera se ocupó de la próxima generación, pues sus cuatro hijos le dieron 17 nietos, 13 de los cuales llegarían a la edad adulta. ${ }^{26} \mathrm{Y}$ parece que fue una buena abuela; por ejemplo, en 1841 llevó a una nieta a la fiesta de San Agustín de las Cuevas y la presentó a la alta sociedad. ${ }^{27}$

Además de ocuparse de asuntos familiares, la viuda María Ignacia estaba por lo menos tangencialmente involucrada en asuntos políticos. El 28 de octubre de 1809 denunció un complot de los “europeos" para envenenar al virrey. Después de determinar que sus acusaciones eran falsas, el virrey Francisco Javier Lizana y Beaumont la desterró de la ciudad de México el 9 de marzo de

${ }^{23}$ Josefa se casó con el Conde de Regla, Antonia con el Marqués de Aguayo y Paz con el Marqués de Guadalupe Gallardo. Sobre sus estudios véase AGN, $I V, M$, c. 159, exp. 47 (1811-12), f. 6v.

24 "Poder" (6 de junio de1809), AGN, IC, I, vol. 1446, exp. 4.

25 Véase "Testamento" (1819), AHN, Francisco de Madariaga \#426, vol. 280, f. 115; AGN, RH, OV, contenedor 11, vol. 24, exp. 6, ff. 511-511v.; AHCM, $A C$, vol. 406, exp. 11 (1818), ff. 28 y 43; y Bustamante, Diario, CD II, apuntes del 8 de enero de 1835 y 12 de julio de 1836.

26 Véase Zárate Toscano, Los nobles ante la muerte, pp. 386, 402, 426-427; y FN.

27 Calderón de la Barca, Life in Mexico, pp. 454-457. 
1810. Aunque el decreto no cita el motivo de su destierro, parece que fue por "perturbar la quietud pública" con sus intentos de apoyar a la facción autonomista respaldada por el Ayuntamiento (que incluía a su padre) y minar la facción propeninsular respaldada por la Audiencia. Según Lucas Alamán “Túvose por cierto que todo este incidente fue originado de intriga fraguada por una señora de una familia distinguida, célebre en aquel tiempo por su belleza, a quien ... [Lizana] desterró en seguida a Querétaro", donde efectivamente la Güera pasó dos meses de su exilio. ${ }^{28}$

Su participación en esta conspiración temprana no es prueba de su apoyo al movimiento independentista posterior, como tampoco lo son las denuncias que le llegaron a las autoridades en dos ocasiones más. El 13 de septiembre de 1810 el tambor mayor Juan Garrido denunció el plan de Hidalgo y afirmó que doña Ignacia Rodríguez “daba el dinero para la revolución”. ${ }^{29}$ En 1814 fue denunciada por "ciertos actos que la hacen la protectora o protegida de los insurgentes". Según una carta sin fecha, atribuida a "María [...] mujer que fue del mayorazgo Villamil", les dio " 500 pesos, piezas de paño para vestir las tropas, papel y otras cosas” y se había comprometido a darles más. La carta se refiere también a unas reuniones con los rebeldes Rafael Vega y Francisco Velasco y a una correspondencia con Leona Vicario. Concluye pidiendo alguna compensación por todas sus "contribuciones y servicios", que a pesar de ser "una mujer sola y desvalida [...] ha sabido exponerse y servir más que los hombres". 30

Lo que no sabemos es si esas contribuciones expresaban un sincero apoyo a la insurgencia o sólo pretendían proteger sus propiedades que estaban bajo el poder de los rebeldes, o si ella

\footnotetext{
28 “Averiguación” (1809-10), en especial el resumen del caso del 20 de enero de 1810, y el decreto del virrey del 9 de marzo de 1810, AGN, IC, IV , c. 4452, exp. 1; y Alamán, Historia de México, t. I, p. 283.

29 "Compendio de la denuncia del tambor mayor del batallón, Garrido" (13 de septiembre de 1810), citado en Castillo Ledón, Hidalgo, t. I, p. 176.

30 Reproducido en Guedea, Prontuario, pp. 364-365.
} 
los hizo de su propia voluntad o porque fue coaccionada. Y cuando inicialmente apoyó a Hidalgo, éste todavía no se había pronunciado en favor de la independencia. Lo único cierto es que la ayuda de la Güera fue bastante discreta y que, al contrario de otras mujeres de la época, ella no sufrió ningún castigo.

Es posible que solamente estuviera cuidando sus intereses porque también mantenía relaciones con firmes adversarios de la independencia. Uno era el canónigo Beristáin, que ofició en las bodas de dos de sus hijas en 1812, al mismo tiempo que predicaba contra los insurgentes. ${ }^{31}$ También tenía contacto con Agustín de Iturbide, antiguo amigo de la familia que se mantuvo leal a España hasta muy avanzada la partida. En dos cartas escritas a su aliado Juan Gómez Navarrete en la primavera de 1809, Iturbide refiere que había visitado a "mi Señora Doña Ignacia” en la casa de sus padres y que habían discutido algún "asunto" que estaba tratando de formalizar-posiblemente algo como instalar a su primo Domingo Malo como administrador de sus propiedades. ${ }^{32}$

Si sus opiniones sobre el movimiento de Hidalgo no quedan claras, su apoyo a la independencia en 1821 es muy probable. De hecho, Iturbide se reunió con el mariscal Francisco Novella y el capitán general Juan O’Donojú el 13 de septiembre de 1821 para negociar la independencia en su Hacienda de la Patera. ${ }^{33}$ Después, durante el Imperio, ella y su familia tuvieron estrechas relaciones con el régimen. Sus hijos, yernos, dos sobrinos y una nieta -pero no ella misma-ocuparon cargos en la corte imperial,

31 Romero de Terreros, Ex-Antiquis, pp. 233, 236; Diccionario Porrúa (1964), p. 186.

32 LadD, The Mexican Nobility, p. 264, nota 119; y cartas de Iturbide a Gómez Navarrete de 31 de marzo y 8 de abril de 1809 en la colección privada de Rodrigo Amerlinck. Le agradezco al Lic. Amerlinck que haya compartido estos documentos conmigo.

33 Alamán, Historia de México, t. V, p. 154. 
su hijo como mayordomo de semana y sus tres hijas como damas honorarias de la emperatriz. ${ }^{34}$

La Güera fue muy visible durante el régimen de Iturbide. En 1822 algunos de sus enemigos hasta circularon el rumor de que "La Huera [era] la reguladora de la conducta de Iturbide y la mano suave que pulsa y mueve las teclas [...] en esta estrepitosa orquesta". ${ }^{35}$ Vicente Rocafuerte iba más allá al afirmar que tenían una relación romántica. En su Bosquejo ligerísimo de la revolución de Mégico, este acérrimo opositor de Iturbide alegaba que él "contrajo trato ilícito con una señora principal de Mégico [...] preciosa rubia, de seductora hermosura, llena de gracias, de hechizos y de talento, $\mathrm{y}$ tan dotada de un vivo ingenio para toda intriga y travesura, que su vida hará época en la crónica escandalosa del Anáhuac". Y aseguraba que esta "rubia Aspasia" fue la que concibió uno de los documentos fundacionales de la historia de México, el Plan de Iguala. ${ }^{36}$

Es imposible determinar la veracidad de estos rumores. Nunca sabremos si en alguna conversación informal ella le haya dicho algo a Iturbide que influyera sobre sus ideas políticas. Pero la mayoría de los cronistas, como Alamán, Zavala y Zerecero -a pesar de no ser amigos de Iturbide-, lo presentaron como el autor del Plan de Iguala y no lo vincularon con la Güera. Solamente Bustamante -y sólo después de leer la Historia de la Revolución hispanoamericana de Mariano Torrente, quien en este tema copió la narrativa de Rocafuerte- mencionó que una señora hermosa "tuvo mucho influjo en este plan" ${ }^{37}$ Rocafuerte fue el único que alegó que ella tuviera un romance con Iturbide. En realidad, es posible que si éste tuvo una amante haya sido la

34 Romero de Terreros, La corte de Agustín I, pp. 20-21; Zárate Toscano, Los nobles ante la muerte, p. 386.

${ }^{35}$ Modesto de la Torre era un soldado español. Citado en Olmedillo, "México", pp. 599-600.

36 Rocafuerte, Bosquejo, pp. 21, 41-42.

37 Bustamante, Suplemento, t. IV, p. 27. 
hija de la Güera, Antonia, la Marquesa de Aguayo, quien también era bella y talentoso y "una de las señoras principales de México”. El diario que llevaba el funcionario español Miguel de Beruete en 1822 contenía dos entradas referentes a esa relación. El 5 de agosto anotó que "La Emperatriz sorprendió a la hija de la Güera con el Emperador”, y el 13 de octubre se refirió a los "lances amorosos del Emperador y la Antonia hija de la Güera". Pero tampoco sabemos si estos chismes eran acertados porque Beruete, un sujeto leal a la corona, no era un observador imparcial. ${ }^{38}$

Sus contemporáneos no repitieron esas historias de amoríos ilícitos. De hecho, parece que pocos mexicanos de la época conocían esos textos escritos por los enemigos del emperador. ${ }^{39} \mathrm{Y}$ si las personas de su círculo social habían oído algunos rumores no le daban mayor importancia: dos años después del fin del Imperio doña María Ignacia se casó con don Juan Manuel de Elizalde, un chileno sumamente respetable que ocupó cargos importantes en el gobierno republicano. ${ }^{40}$

38 Beruete nunca aceptó la independencia de México y consideraba a Iturbide un traidor a la madre patria. Véase Beruete, Elevación y caída, pp. 51, 70, y "Prólogo" de Henestrosa, p. 11.

${ }^{39}$ El libro de Rocafuerte, publicado bajo un pseudónimo en Filadelfia en 1822, casi no se conocía en México. Alamán si lo leyó, pero lo descartó como una obra de propaganda llena de mentiras para "hacer odioso a Iturbide", Historia, t. V, p. 53, n. 51. En 1829-1830 Mariano Torrente repitió algunas de las alegaciones de Rocafuerte en su Historia de la Revolución, t. III, pp. 135136, pero la sección sobre la Güera se difundió con la publicación del volumen condensado sobre México en 1918: Torrente, Historia de la Independencia, pp. 276-277. El diario de Beruete no se descubrió sino hasta 1932, y el de Torre todavía no se había publicado en 1960 . Véanse los prólogos a estas obras y el artículo de Olmedillo.

${ }^{40}$ Los puestos de Elizalde incluyen ser alcalde primero del ayuntamiento en 1826, gobernador del Distrito Federal en 1827, diputado de la Cámara de Representantes entre 1830-1837, y desde 1848-1857 cónsul general de Chile en México. AHN, Francisco de Madariaga \#426, vol. 2837 (1826), f. 336v., vol. 
Sabemos muy poco de los siguientes 25 años de su vida. $\mathrm{Pa}$ rece que su tercer matrimonio fue tranquilo. En su testamento de 1850 la Güera elogia la "religiosidad y suma honradez" de su marido, que había arreglado "el desorden en que se hallaban mis papeles". ${ }^{41}$ Tanto Fossey como Calderón observaron a la señora Elizalde participando con entusiasmo en el torbellino social de la capital. Además seguía activa en la vida cívica: durante la guerra con Estados Unidos se unió a otras 13 señoras (entre ellas su hija Antonia) para formar una junta que apoyaba los hospitales de sangre que atendían a los soldados heridos y organizó un concierto de beneficio el 26 de diciembre de $1846 . .^{42}$

Hacia el final de sus días es posible que la Güera haya quedado inválida: su certificado de defunción, fechado el 1o de noviembre de 1850, la califica de "paralítica". ${ }^{43}$ Fue enterrada en la iglesia de San Francisco de la ciudad de México, en la misma calle donde pasó la mayor parte de sus 71 años. Había sobrevivido a sus padres, sus dos hermanas, dos maridos y cinco de sus siete hijos.

SU VIDA PÓSTUMA: LOS PRIMEROS 100 AÑOS

Después de su muerte María Ignacia Rodríguez desapareció de las letras mexicanas hasta principios del siglo xx. No es que las narrativas del siglo XIX ignorasen por completo a las mujeres. Ya en 1825 se publicó un calendario "dedicado a las Señoritas americanas" que alababa las valerosas acciones de una docena

2838 (1827), f. 26v., y vol. 2846 (1834), ff. 229-32; y Diccionario Porrúa (1995), t. III, pp. 1175-1176.

41 “Testamento" (1850), AHN, Francisco de Madariaga \#426, vol. 2873, f. 600.

42 “Avisos: Gran Concierto", El Monitor Republicano (25 dic. 1846), p. 4.

43 Partida de muerte (10 de noviembre de 1850), APA, Entierros, libro 29, núm. 2220 , f. 30. 
de patriotas mexicanas; y algunas fueron reconocidas en vida. ${ }^{44}$ Pero la Güera no figuraba entre éstas. Tampoco apareció entre los mexicanos distinguidos retratados por Francisco Sosa en su compendio biográfico de 1884, ni entre el centenar de mujeres notables mexicanas retratadas por Laureana Wright de Kleinhans a finales del siglo. ${ }^{45} \mathrm{Ni}$ en las celebraciones del centenario del Grito de Dolores. ${ }^{46}$

Su resurrección comenzó con algunas publicaciones eruditas que llegaban a un público bastante restringido. Pocas de éstas se basaban en investigaciones históricas, aunque se nutrieron de nuevas ediciones de los textos olvidados de la primera mitad del siglo XIX -sobre todo La vida en México, de Fanny Calderón, que apareció por primera vez en una traducción al español en 1920-.47 Algunos documentos recién descubiertos aportarían detalles adicionales para su futura fama. Pero la Güera todavía no era ninguna celebridad ni era conocida como una heroína de la independencia.

Fue la publicación en 1906 de las Memorias de mis tiempos de Guillermo Prieto lo que la trajo de vuelta a la luz pública. ${ }^{48}$ Ella aparece dos veces en ese libro chismoso: en una frase sobre los "viejos verdes" que se referían a "los agudísimos dichos de la güera Rodríguez”; y en una...página en que se lee:

${ }^{44}$ Fernández de Lizardi, Calendario. Sobre el temprano reconocimiento de otras heroínas véase, por ejemplo, Bustamante, Cuadro, t. I, p. 16 y t. II, p. 200; y Tecuanhuey, "Imagen".

${ }^{45}$ Si bien el libro de Wright de Kleinhans se publicó en 1910, después de la muerte de la autora en 1896, los retratos individuales aparecieron a finales del siglo xix en su revista Violetas de Anábuac. Véase Pouwels, Political Journalism, pp. 29-44. También F. SosA, Biografías.

46 Véanse Moreno Juárez, "Presencia”; y Agüeros y Peza (coords.), Episodios, t. I, pp. 259-269 y t. II, pp. 213-230 y 253-260.

47 Véase el ensayo de los editores al final de CALDERón DE la BARCA, Life in Mexico, p. 636.

${ }^{48}$ Prieto, Memorias, t. I, p. 237, y t. II, p. 318. 
Frente por frente de la Profesa pasó sus últimos días, casada con don Juan Manuel Elizalde, la Güera Rodríguez, llamada la Venus mexicana por su soberana hermosura que ensalzó en su obra el barón de Humboldt [...] La amistad que le profesó Iturbide, se decía, tuvo grande influjo en la Independencia. Este influjo era tal, que aseguraban los contemporáneos, que habíendose determinado [...] que la entrada del Ejército Trigarante se hiciese por la Calle de Tacuba, no se verificó sino por las de San Francisco y la Profesa, porque así lo quiso la dama favorecida por el caudillo de las Tres Garantías.

Ésta fue la primera mención impresa de la anécdota que después se ha repetido muchas veces: que Iturbide cambió la ruta de su desfile triunfal del 27 de septiembre de 1821 para pasar frente al balcón de la Güera. Es difícil saber si contiene algo de verdad. No aparece en las muchas descripciones anteriores del acto. Alamán, por ejemplo, relata que el ejército entró por la calle de San Francisco, donde los regidores esperaban para entregarle a Iturbide las llaves de la ciudad, y siguió hacia el palacio virreinal por un camino que de todos modos habría pasado directamente por su casa. ${ }^{49}$ Además, pese a que el título implica que Prieto narra sus memorias, su información sobre este incidente es de segunda mano, pues la entrada de Iturbide tuvo lugar cuando él apenas tenía tres años. Prieto cita como fuente lo que decían los contemporáneos de la Güera, pero para cuando él escribió su libro -entre 1886 y 1897-50 la mayoría de éstos había muerto, lo que significa que se basaba en su recuerdo de los recuerdos de otros, una fuente poco confiable.

Cierto o no, en estas breves líneas Prieto le recordó al público que en México hubo una vez una mujer muy linda y chistosa; revivió la memoria de su estrecha amistad con Iturbide; la colocó en el centro de un acontecimiento histórico importante;

49 Alamán, Historia de México, t. V, p. 167.

50 Véase Curiel, "Prólogo", t. I, p. 46. 
y le dio el apodo de "la Venus mexicana" que contribuiría a su posición casi mítica, puesto que Venus era la diosa del amor, fertilidad y sexo.

El segundo paso en su camino hacia la fama se debe a tres libros publicados por su tataranieto, Manuel Romero de Terreros y Vinent, entre 1909 y $1921 .{ }^{51}$ Este gran historiador del arte también es uno de los primeros historiadores sociales, parte de una generación que reaccionó contra las crónicas políticas del siglo XIX rescatando cuadros de la vida diaria y afirmando que la época colonial formaba parte legítima de la historia nacional. Se fijó mucho en la Güera Rodríguez porque ella también le servía para exaltar a sus antepasados. Por lo tanto, la presenta como una gran dama intachable, "la figura de mayor relieve, socialmente hablando, que había habido en México durante los siglos XVIII y XIX". Y nos cuenta una serie de anécdotas que destacan sus lazos con los nobles, los famosos y los poderosos; hacen resaltar su religiosidad y caridad, y afirman su constante patriotismo. Claro que el autor niega que su tatarabuela fuera amante y consejera de Iturbide, afirmación que había leído en la obra de Rocafuerte.

Dos ejemplos dan una idea de las contribuciones de Romero de Terreros al mito de la Güera. Uno es la historia de cómo, después de la defunción de su segundo marido, ella ganó su batalla con la familia Briones sobre la herencia. Como ellos la acusaban de fingir un embarazo, "doña Ignacia [...] decidió que el nacimiento de su hijo fuera delante de testigos; pero como el suceso acaeció antes de lo que se esperaba, vióse la Güera precisada a llamar a su alcoba a algunas personas que en esos momentos transitaban por la calle, para que dieran fe de la autenticidad del acontecimiento". De hecho, es verdad que los hermanos de

51 Véase Romero de Terreros, Los Condes, p. 86; Ex-Antiquis, pp. 224-236; y La Corte de Agustín I, pp. 5-10. Las citas vienen del capítulo "Venus y las Tres Gracias", en Ex-Antiquis. 
Briones la demandaron para conseguir una porción del legado y hasta pidieron que un cura de la ciudad de México testificara sobre si ella estaba embarazada, que en efecto estaba. ${ }^{52}$ También es verdad que a la muerte de su hija póstuma la Güera se quedó con todo, y que para poner fin al pleito les dio el quinto de los bienes que había heredado. ${ }^{53}$ Pero no hay evidencia que nos permita confirmar el resto del cuento. De todas formas, la nueva anécdota la pinta como una mujer audaz y recuerda la práctica de la realeza española de llamar testigos para presenciar el nacimiento de un vástago.

Otro párrafo destaca el papel de la Güera en el movimiento de independencia:

[...] en el año de 1810 fue citada ante el tribunal de la Inquisición para responder a los cargos que se le hacían por haber conspirado en contra del Gobierno. Acaeció que los jueces de la temida institución eran de ella muy conocidos y allegados y, después de un proceso que rayó en lo jocoso [...] [se] le impuso como castigo un corto plazo de destierro a la ciudad de Querétaro, pena que cumplió con el mayor desenfado. No abandonó su simpatía por la Independencia y, años más tarde, tuvo grande amistad con Iturbide, quien la distinguió a tal grado, que se asegura que la entrada del ejército trigarante [...] se hizo por [...] [la calle] de San Francisco, con el objeto de que ella pudiera admirarlo desde su casa [...]; y al pasar delante de dicha casa, el futuro emperador de México detuvo un momento la marcha y, desprendiendo de su sombrero una de las plumas tricolores que en él llevaba, la envió con uno de sus ayudantes a la hermosa 'Güera'.

52 "Solicitud", AGN, $I V$, C, c. 5122, exp. 18 (31 de mayo, 1808), ff. 1-2v.; y AHN, José Ignacio Moctezuma \#158, vol. 959 (29 de agosto de 1807), f. 130v. 53 Véase AHN, Francisco de Madariaga \#426, vol. 2830 (1을 abril de 1819), ff. 115-115v.; vol. 2838 (12 de enero de 1827), ff. 27-28; y vol. 2852 (21 de febrero de 1837), ff. 191-193. 
Otra vez, esta historia contiene un granito de verdad, pero también varias inexactitudes. Si bien el virrey la llamó a reunirse con él en noviembre de 1809 (no en 1810), nunca hubo un juicio formal ante el tribunal. Además, no fue desterrada por abogar por la independencia sino por estar metida en una temprana intriga con posible tinte autonomista. Y la descripción de la entrada triunfal de Iturbide solamente repetía -y adornaba- el cuento cuestionable de Prieto, añadiendo el detalle de que le obsequió una pluma de su sombrero.

No está claro en qué se basa Romero de Terreros para estas anécdotas. Para algunas cita los textos de Alamán, Prieto, Calderón de la Barca y Rocafuerte, pero las otras solamente se las atribuye a lo que "cuenta la crónica". Algunas historias resultan totalmente falsas: por ejemplo, que la Güera legó sus espléndidas joyas a una imagen de la iglesia de la Profesa, cuando su último testamento dice claramente que ya las había regalado todas en vida. E incluso muchas de sus fechas son erróneas, como el año de su muerte, que da como 1851 (fue 1850), error que se ha repetido muchas veces. ${ }^{54}$ No obstante, sus cuentos entretenidos sobre Venus y las Tres Gracias (sus tres hermosas hijas) siguieron siendo parte de la leyenda para siempre.

Al mismo tiempo la historia de su relación con Humboldt estaba resurgiendo y volviéndose más fantasiosa. En un estudio de 1910, Arnoldo Krumm-Heller afirma que éste sintió "una pasión honda" por la bella joven que hasta lo distrajo de sus estudios. Desde luego se trataba de un amor “casto", pero era una emoción tan "profunda” que no podía olvidarla después de regresar a Europa ${ }^{55}$ Krumm-Heller no aporta ninguna información nueva para respaldar sus afirmaciones; su única fuente era

${ }^{54}$ AHN, Francisco de Madariaga \#426 (16 de agosto de 1850), ff. 599-599v. Entre los muchos otros errores está el nombre de su segundo marido, a quien llama Mariano cuando en efecto era Juan Ignacio.

55 Krumm-Heller, "Esbozo biográfico”, pp. 20, 23-25. 
el manido trozo de la carta que Fanny Calderón escribió el 1으 de febrero de 1840 después de su primer encuentro con la Güera.

E incluso ese relato debe ser examinado más a fondo, porque se basa enteramente en lo que la propia Güera le contó a Fanny casi 40 años después de la visita de Humboldt. Es posible que ella haya exagerado su amistad con el famoso científico para impresionar a la nueva visitante. Y parte de la información en Life in Mexico es inexacta: María Ignacia tenía 24 años, no 18, cuando conoció a Humboldt, y en 1803 tenía cuatro hijos, no tres como dice Fanny. Además, la Güera no alude a ningún lazo romántico con Humboldt; al contrario, presenta su relación como una de compañerismo y curiosidad intelectual compartida. Si bien Fanny agrega la sugerencia de que él estaba "fascinado" por la bella mujer y se permitió un "pequeño coqueteo", se pueden ver esos comentarios como un intento de sazonar la historia para los lectores, puesto que la escritora ya pensaba en publicar sus cartas en forma de libro de viaje. ${ }^{56}$ En cualquier caso, hay una diferencia enorme entre la amistad que describe Fanny y la profunda -aunque casta- pasión a que alude Krumm-Heller. Dos historiadores que estudiaron a Humboldt desecharon por completo esa historia. Es más, Juan Ortega y Medina llegó a la conclusión de que la leyenda "donjuanesca" se había creado para compensar la "tendencia homosexual decidida" del gran hombre. ${ }^{57} \mathrm{Y}$ sin embargo el cuento del romance persistía.

También estaba apareciendo información nueva que la vinculaba más estrechamente con la rebelión de Hidalgo. En su colección de Documentos históricos de 1910, Genaro García reprodujo el documento de 1814 en que las autoridades pedían información sobre las contribuciones de María Ignacia

56 Calderón de la Barca, Life in Mexico, p. 141.

57 Ortega y Medina, Humboldt, esp. pp. 167-173, 217; y Alessio Robles, “Introducción”, en su edición del Ensayo político de Humboldt, t. I, pp. 80-81. 
Rodríguez a los rebeldes..$^{58}$ Otro documento publicado en 1932 decía que Ramón Cardeña, “el Cura Bonito” conocido como opositor al gobierno colonial, "se había enredado con la Güera Rodríguez” en 1817. La implicación es que se trataba de alguna conspiración política -aunque sabemos por su testamento de 1819 que su antiguo amigo le debía 25000 pesos, probable tema de su visita-.${ }^{59}$ En 1946 Elías Amador agregó otro detalle hasta entonces desconocido. Una breve entrada en sus Noticias biográficas de insurgentes apodados cita la denuncia de Garrido y concluye que la Güera Rodríguez "sin duda alguna profesaba marcado afecto a la causa de la Independencia, pues se dice que [...] se había ocupado de proporcionar dinero al Cura Hidalgo para ayuda de la revolución". ${ }^{60}$

Haría falta tiempo para que ese nuevo material llegara a la literatura más popular. Los libros sobre "mujeres célebres" seguían sin mencionarla. ${ }^{61}$ Todavía en 1964 el Diccionario biográfico de Juan López de Escalera, que incluye muchas heroínas de la independencia, la ignora. Sin embargo, las referencias a la Güera Rodríguez aparecían con más frecuencia.

\section{LA LEYENDA CRISTALIZADA POR VALLE-ARIZPE}

Aunque algunos estudiosos de la historia de México ya la conocían, María Ignacia Rodríguez entró a la imaginación popular en 1949 con La Güera Rodríguez de Artemio de Valle-Arizpe. El libro es una delicia de leer. Su decisión de usar como título el

58 “Oficio de D. José Antonio de Noriega” (19 de julio de 1814), en García, Documentos históricos, t. V, pp. 461-462.

59 "Denuncia del alcaide y el teniente de las cárceles secretas del Santo Oficio" (26 de septiembre de 1817), en Boletín del Archivo General de la Nación, vol. 2, núm 3 (julio-septiembre de 1932), pp. 334-345; y AHN, Francisco de Madariaga \#426, vol. 2830 (1을 de abril de 1819), f. 115.

60 Amador, Noticias biográficas, p. 51.

${ }^{61}$ Por ejemplo, Rubio Siliceo, Mujeres célebres y Fernández y Fernández, Mujeres. 
apodo de la protagonista también contribuyó a hacerla memorable. La obra fue una sensación inmediata que hizo que generaciones de mexicanos se enamoraran de ella, y todavía se lee en una edición de 2011 que agrega el subtítulo "Relatos reales del sorprendente y divertido personaje de la historia de México". ${ }^{62}$

Valle-Arizpe (1888-1961) fue un diplomático y prolífico autor de docenas de libros sobre temas históricos, además de 14 obras de pura ficción. ${ }^{63}$ Como su Güera Rodríguez incluye una breve bibliografía y largas citas de documentos originales, muchos lectores han supuesto que es una biografía fidedigna. Sin embargo, debemos considerarla una novela histórica porque combina historia con ficción. Al incluir hasta los cuentos más extravagantes sin evaluarlos, Valle-Arizpe los propagó aún más, y además introdujo algunos completamente nuevos de los que no da ninguna prueba.

De hecho, Valle-Arizpe fue quien originó muchos de los mitos que desde entonces se asocian con la Güera. Algunos inventos son pequeños detalles, por ejemplo, que ella se había casado en la catedral (fue en la capilla del Hospital de Betlemitas), o que ella fue quien había acuñado el dicho "Fuera de México, todo es Cuautitlán”. ${ }^{64}$ Otros inventos tendrían más peso, en particular

${ }^{62}$ Valle-Arizpe revisó el texto varias veces entre 1949 y 1956. Las nuevas ediciones incorporaron materiales que él iba descubriendo, como Le Mexique de Fossey y la Historia de Torrente; hicieron cambios estilísticos y agregaron algunas notas a pie de página (algo que no existía en la primera edición). Las ediciones revisadas, a pesar de ser más largas que la primera y dar más detalles sobre algunos incidentes históricos, no cambiaron la estructura del libro ni la representación de la Güera.

${ }^{63}$ Fue miembro de la Academia Mexicana de la Lengua desde 1924 y designado cronista de la ciudad de México en 1942. "Artemio de Valle-Arizpe", en http://es.wikipedia.org/wiki/Artemio_de_Valle_Arizpe, consultado el 23 de junio de 2016; Diccionario Porrúa (1964), p. 1530. Estas fuentes dan diferentes fechas de nacimiento: 1884 vs. 1888.

${ }^{64}$ Véase Acta de Matrimonio (7 de septiembre de 1794), APA, Matrimonios Españoles, libro 35, f. 176v., núm. 154. El dicho popular no aparece en ninguna obra o documento sobre la Güera antes de 1949. 
sus supuestos amoríos. "Aparte de sus tres amores lícitos”, nos dice, "tuvo [...] otros casamientos en los que no tercia Dios. Galantes devaneos que le pedía su alma, siempre con sed de amor”. Sus amistades con Humboldt e Iturbide -que efectivamente existieron- se convirtieron en apasionados romances, relatados en el estilo tórrido de las novelas románticas. La Güera elevó a Humboldt "de lo humano de la ciencia a lo divino del amor". "Fue la sirena que le cantó y él dejóse perder muy contento." Los dos "casi no se apartaban [...] Eran por unión un cuerpo y un alma”. Ella e Iturbide también "estaban presos y encadenados de amores”. Y los cuatro señores a quienes Villamil acusó -sin ninguna prueba- de cometer adulterio con su esposa en 1801 y 1802 se convirtieron en indiscutibles amantes. ${ }^{65}$

Valle-Arizpe también introdujo nuevos amantes que no aparecían -ni como amigos- en los documentos históricos. El primero fue Simón Bolívar, quien pasó una semana en la ciudad de México en 1799, cuando tenía 17 años, pero nunca antes había sido relacionado con la Güera. (Parece que Valle-Arizpe había leído que Bolívar se alojó en una casa perteneciente a su hermana, la Marquesa de Uluapa, y ese detalle fue suficiente para inflamar su imaginación. Lo que el autor no sabía es que la marquesa no vivía en esa casa durante la visita de Bolívar sino que la tenía alquilada al oidor Guillermo Aguirre). ${ }^{66}$ Valle-Arizpe también afirma que después, entre el segundo matrimonio y el tercero, la Güera tuvo una serie de amantes -aunque no da sus nombres, porque eran totalmente ficticios. Desterrada a Querétaro, "la Güera, para amenizar [...] el aburrido destierro [...] se ocupó activamente en la busca y rebusca de galanteces” (Ahora sabemos que en realidad pasó esa época enferma en cama y

65 Valle-Arizpe, La Güera Rodríguez, pp. 79, 139, 148-149, 181.

66 Sobre el alquiler, véase AGN, VM, vol. 225, exp. 1 y vol. 223, exp. 6. Tanto Romero de Terreros como Valle identificaron la casa como de la hermana de la Güera. Romero de Terreros, Ex-Antiquis, p. 233 y Valle, Bolivar en México, p. ix. 
cuidando de su hija moribunda). ${ }^{67}$ Tras su regreso a la ciudad de México "tuvo muchos y buenos galanes" y se "recreó [...] con un médico gordo [...] un sapientísimo maestro [...] un poderoso abogado" y otros con que "suministraba a su pasión continuo alimento [...] pues ganó las inclinaciones de mozos fornidos y vigorosos, bestias magníficas de gran aguante en los caminos del amor" ${ }^{68}$

Al tratar de explicar los toques ficticios que agregó a su narrativa, he llegado a la conclusión de que Valle-Arizpe no intentaba engañar a sus lectores, sino que se estaba dando el gusto de escribir una obra amena con fines didácticos.

Primero, estaba haciendo de la Güera un Don Juan femenino, y así sumándose a la fila de autores que han reescrito esa famosa obra. De hecho, inmediatamente después de la lista de conquistas citada más arriba, Valle-Arizpe observa que ella era una “doña Juana Tenorio". Esa referencia a la popular obra de José Zorrilla, de 1844, revela la fuente de su inspiración para muchas de las invenciones de La Güera Rodríguez. ${ }^{69}$

Desde el principio Valle-Arizpe da indicios de que se trata de una obra de ficción: su prólogo advierte sobre la naturaleza "picaresca" de su relato, y su decisión de llamar a las secciones “jornadas" en vez de "capítulos" evoca los términos empleados para los actos en el teatro del Siglo de Oro. Cuando nos relata los días (es decir, las jornadas) de la Güera, nos está relatando también su viaje (también jornada) en busca de la felicidad. Su búsqueda la llevó a un primer matrimonio infeliz, un breve segundo matrimonio truncado por la muerte y numerosas aventuras amorosas que la conducían por el camino errado hasta que encontró la paz y la satisfacción en los brazos de su último

\footnotetext{
67 Véanse sus tres cartas al virrey pidiendo que se le levantara el destierro (17 de marzo, 14 de abril y 28 de abril de 1810), “Averiguación”, AGN, IC, IV, c. 4452 , exp. 1 , ff. 100-108.

68 Valle-Arizpe, La Güera Rodríguez, pp. 170-172.

69 Zorrilla, Don Juan Tenorio. Véase también Mandrell, Don Juan.
} 
marido, que calmó a la ardorosa viajera y la trajo de vuelta a la domesticidad y la fe. Por lo tanto, muchas de sus invenciones eran necesarias para la trama en que la protagonista libertina es redimida por el amor.

Esta lectura explica no sólo “sus amores continuos” sino también la representación casi pura ficción de sus últimos años. El capítulo sobre su tercer matrimonio alaba la "gloria” del buen matrimonio que "al fin sosegó su vida [...] al amortiguarle la libídine, se la pacificó, la puso en orden”. Ella “dejó visitas, dejó paseos, tertulias y saraos” y sólo salía para ir a la iglesia y practicar obras de caridad. Así Elizalde cumplió “la ardua [...] tarea” -supuestamente confiada por Dios en primer lugar a Iturbide- "de traer al buen camino a la tempestuosa Güera Rodríguez" ${ }^{70}$

Valle-Arizpe además agrega un segundo tema a la búsqueda de la Güera: su deseo de ver a México separado de España. Su presentación de las actividades políticas de la protagonista va mucho más allá de la documentación histórica. Afirma que la dama escandalizó a la sociedad apoyando abiertamente la rebelión de Hidalgo y maldiciendo en público "esa vil alimaña de Fernando VII”; es más, la retrata como una traidora a su clase, repitiendo el lugar común (y falso) de que "todos los ricos [...] eran realistas”. Según Valle-Arizpe, Hidalgo la visitaba regularmente cuando iba a la ciudad de México. Una de las escenas más dramáticas es su proceso (inventado) frente a un panel de inquisidores, que el autor erróneamente ubica en el otoño de 1810, más de seis meses después de la fecha en que ella ya había sido desterrada de la capital mexicana. La "valiente” Güera se presentó ante los severos jueces con el mayor sosiego. Los miró directamente a los ojos y procedió a enumerar sus vicios y pecadillos, desafiándolos a condenarla si querían que todo el mundo conociera esos secretos. Los tres temibles jueces, "que

70 Valle-Arizpe, La Güera Rodríguez, pp. 64-65, 192, 213. 
a los muy hombres les helaban la sangre [...] los derribó con la filosa espada de su lengua". ${ }^{71}$

El capítulo sobre su relación con Iturbide también contiene muchos "datos falsos". En buena parte se basa en los rumores originados por los enemigos de Iturbide en 1822, ampliados por su fértil imaginación. Según su relato la Güera era la mente maestra de la independencia: fue ella quien convenció a Iturbide de cambiar de bando, la que propuso a los conspiradores de la Profesa que lo hicieran su comandante militar, y la que imaginó el Plan de Iguala. Si no ocupó ningún cargo en la corte imperial fue porque "ella tenía puesto muy firme y principal en el corazón de Iturbide". ${ }^{72}$ Valle-Arizpe añade que ella le advirtió que no intentara ponerse una corona en la cabeza, pero que él ignoró sus consejos. En consecuencia, Iturbide cayó ignominiosamente, mientras que la Güera sobrevivió como una heroína resplendente. No sólo fue mucho más astuta que él, sino que estuvo firmemente comprometida con el republicanismo -interpretación que la prominencia de su familia en la corte imperial contradecía.

Además de permitirle a Valle-Arizpe adaptar uno de los cuentos más famosos de la literatura universal, La Güera Rodríguez fue parte de su proyecto vitalicio de crear una cultura nacional. Al centrar la historia patria en la bella dama y relacionarla con tres de los hombres más famosos de la época, pudo escribir una narrativa que contaba en detalle el camino de México hacia la independencia. Y como su relato era tan divertido, pudo amenizar "la almidonada escena de la Independencia Nacional" y hacerla más atractiva para sus lectores en una época en que se expandía el mercado de libros y crecía el público lector. ${ }^{73}$ También le permitió crear orgullo patriótico. El texto está lleno de superlativos. ${ }^{74}$

71 Valle-Arizpe, La Güera Rodríguez, pp. 154-155, 159-163.

72 Valle-Arizpe, La Güera Rodríguez, pp. 181-187, 207.

${ }^{73}$ Blanco, Álbum de pesadillas mexicanas, pp. 19-21.

${ }^{74}$ María Guadalupe Sánchez Robles observa la frecuencia de los superlativos como una de las estrategias literarias que Valle-Arizpe utiliza para mitificarla: 
México tenía la mujer más hermosa de todo el continente, una figura "extraordinaria” y "original”. ${ }^{75}$ De hecho, México tenía su propio Don Juan, una versión muy mejorada porque el protagonista era una mujer con un corazón puro y la historia tenía un final mucho más feliz que en la versión de Zorrilla, en que Don Juan se salva solamente en el momento de su muerte.

Su representación de la Güera también refleja la ambivalencia del autor hacia los cambios en la posición de la mujer para la década de 1940. Por una parte, Valle-Arizpe quiso celebrar los logros femeninos. Al hacer de una mujer un agente activo del cambio, en lugar de un simple objeto del deseo sexual y de poder de los hombres, revela nuevas actitudes hacia las mujeres. La "exuberancia vital” de su protagonista para él era una fuerza positiva, y su supuesto desafío a las costumbres sociales restrictivas un saludable signo de la llegada de un mundo moderno en que los individuos podían libremente buscar su felicidad. ${ }^{76}$ Pero, por otra parte, la influencia de la Güera se mantenía tras bambalinas y se ejercía por medio del amor, porque cualquier otra forma de poder femenino habría sido ilegítima. Si Iturbide la visitaba y consultaba, por ejemplo, tenía que ser porque eran amantes, y no porque él pudiera apreciar sus opiniones o tuviera que discutir algún asunto de negocios (lo que era mucho más probable). Y los detalles risqués del relato -necesarios para la trama- estaban incrustados en una alegoría moral que los hacía aceptables. La narración tenía una resolución tradicional: al final del cuento era necesario aplacar el fuego de la Güera y contenerla con un buen matrimonio y el retorno a la piedad. Por lo tanto, ella ni representaba la liberación femenina ni amenazaba al patriarcado en esta versión de su vida.

Sánchez Robles, “La Güera Rodríguez”, pp. 364-369.

75 Valle-Arizpe, La Güera Rodríguez, pp. 24, 26, 213, 261.

76 Valle-Arizpe, La Güera Rodríguez, p. 172. 
Estas perspectivas no sólo explican muchas de las invenciones de Valle-Arizpe sino también las omisiones que impiden que La Güera Rodríguez sea una biografía completa. La narrativa destaca sus supuestas relaciones amorosas y sus actividades políticas, mientras que resta importancia a otros aspectos de su vida, como su desempeño de los papeles de madre, abuela e hija, o sus aprietos financieros. Y parece que Valle-Arizpe poseía información para decir más sobre éstos: por ejemplo, observa que tuvo en sus manos dos gruesos paquetes de cartas que ella le escribió a su hijo Jerónimo y a su nieto Manuel Romero de Terreros. Pero los descartó como "simples cartas familiares sin ninguna importancia". ${ }^{77}$ Esa falta de interés por los aspectos mundanos de la vida de doña María Ignacia Rodríguez nos recuerda que el objetivo de Valle-Arizpe nunca fue simplemente contar su historia.

\section{LA GÜERA DE VALLE-ARIZPE TOMA VIDA PROPIA}

La trayectoria de la Güera después del libro de Valle-Arizpe demuestra el poder que puede tener una buena obra de ficción. La figura que él había creado se diseminó, no solamente por el éxito de su texto, sino gracias a que nuevos narradores quisieron contar sus cuentos y otros quisieron creérselos. Aunque la fuente principal de esas representaciones era la novela de Valle-Arizpe, la nueva Güera Rodríguez no era una copia exacta de su creación. Algunos nuevos "datos falsos" se fueron introduciendo y repitiendo: por ejemplo, que ella fue el modelo para la escultura de la Virgen de los Dolores en la iglesia de la Profesa (fue su hija Paz), y que ella fue quien inició el divorcio y lo obtuvo (a pesar de que fue él y la pareja se reunió después de que el proceso

VAlle-Arizpe, La Güera Rodríguez, pp. 257-258. 
fuera suspendido sin resolución). ${ }^{78} \mathrm{Su}$ identidad de gran dama aristocrática -tan importante para Romero de Terreros- se fue amainando a medida que adquiría una conciencia social y solidaridad con los pobres. Además, el capítulo final de su vida, tan importante para Valle-Arizpe-su conversión a la domesticidad y la fe-, desapareció de la mayoría de los textos posteriores, porque esa narrativa ya no atraía a los mexicanos de fines del siglo xx y comienzos del xxi. Algunos ejemplos darán idea de sus transformaciones.

El auge del movimiento feminista en México durante la década de los setenta le dio nueva vida a la figura de la Güera Rodríguez. Al buscar figuras de mujeres en la historia de México los nuevos narradores encontraron a la seductora Güera Rodríguez de Valle-Arizpe, pero también la cambiaron. Ahora se convirtió en una heroína indomable. Lo que la hacía una favorita para la nueva época eran su glamur y sexualidad, su fuerza e independencia, su inteligencia y su compromiso político. Y ahora se celebraba como mujer emancipada -aunque los misóginos (en un número mucho menor de retratos, todos de hombres) la calificaban de puta-. Es decir, que podía ser vista como la encarnación o la violación del ideal femenino, fuente de la ambivalencia que la hace $\tan$ interesante.

En 1977 la Güera dió un paso desde la memoria literaria hacia la popular en una película suntuosamente sensual, La Güera Rodríguez, dirigida por el célebre cineasta Felipe Cazals y protagonizada por la voluptuosa actriz Fanny Cano. Esta producción

${ }^{78}$ Según Prieto el modelo para la estatua de la virgen fue su hija, Paz (Memorias, t. II, p. 318), afirmación copiada por Romero de Terreros y Valle-Arizpe. Pero con el tiempo la hija y la madre se confunden: véase, por ejemplo, Garci, quien asegura que la imagen de la virgen (que identifica como la Virgen de la Purísima) es la Güera. Garci, Más pendejadas, p. 18. La invención de que ella inició el divorcio aparece en la historieta de BASTIEN y Plaza, "La Güera Rodríguez", p. 23; y de que lo obtuvo, en Arrioja Vizcaíno, El águila en la alcoba, pp. 58-61. 
presentó a la Güera como una versión fílmica de "La rubia que todos quieren"79 -una importante heroína de la independencia, en que resalta su sexiness como parte de la estrategia de comercialización-. La propaganda publicitaria marcaba el tono al afirmar que "toda una época" se asomó a sus escotes..$^{80}$

La película añade muchos elementos nuevos a los cuentos de Valle-Arizpe. Por ejemplo, en su supuesto encuentro con el panel de inquisidores, la Güera ahora los acusaba de pederastia. Cuando su marido disparó contra ella fue porque encontró a Bolívar saltando de su balcón, pese a que el Libertador (a quien quizá ni siquiera conoció) había abandonado México años antes del incidente. Y hay escenas maravillosas (y totalmente inventadas) en que la Güera esconde un cargamento de armas en su vestidor o se reúne con la Corregidora para discutir la estrategia para lograr la independencia. Pero la película no presenta a Iturbide como su amante y termina antes de que la heroína fuera manchada por su complicidad con el Imperio. Como advirtieron los autores del guión en una nota escrita a mano: "Si lo que relatamos no sucedió exactamente, nos hubiera gustado que así hubiese sucedido".

La película refleja lo que el público deseaba y a la vez temía, pues sus diálogos encarnan las tendencias feministas y contraculturales de los años setenta. Así, la Güera declara: "entro donde quiero y no me gusta que me maltraten", y "en un ambiente medroso [y] pequeño [...] alguien que simplemente aspire a divertirse un poco [...] alguien irreverente, espontáneo y sincero causará escándalo". En varias escenas hace frente al virrey y a los hombres de su vida. Por ejemplo, cuando Elizalde inicialmente le proclama su amor, pero dice que él quisiera

\footnotetext{
79 Éste fue el lema publicitario de la cerveza Superior en esa época. Le agradezco a Myrna Vázquez haberme recordado este detalle.

${ }^{80}$ Véase el guión de Julio Alejandro y Emilio Carballido, notas y reseñas en "Datos de la Ficha", FUNAM, exp. No. A-00399. Este acervo también tiene una copia incompleta de la película.
} 
llevar los pantalones en la familia "como un hombre chapado a la antigua”, ella lo deja ir, con lágrimas en los ojos. En otra escena declara que quería ser libre, no sólo como ciudadana sino también como mujer. En cierta medida esta Güera era la perfecta fantasía masculina: bella y accesible. Pero también era una fantasía femenina: ambiciosa y liberada.

En 1990 la Güera apareció en otro medio visual que quizá haya llegado a un público más amplio: una historieta de la exitosa serie Hombres y Héroes. ${ }^{81}$ El número 158 se dedicó a "La Güera Rodríguez: bella conspiradora mexicana”. Igual que la película, el cómic revolvía datos y fechas -y contenía ilustraciones cuasi-eróticas de la Güera, obligatorias en este género-. No obstante, el texto la representa más como patriota que como adúltera. Empieza en 1804 con la escena en que su primer marido le dispara un pistoletazo (hecho que en realidad sucedió en 1802), supuestamente por encontrarla con los cuatro señores que acusó de ser sus amantes. Pero en esta versión la Güera se había reunido con ellos solamente para conspirar por la independencia (algo muy poco plausible en esa temprana fecha). De hecho, sus convicciones políticas eran tan fuertes que fue ella quien alentó al joven Bolívar para seguir su sueño de conseguir la independencia. Y ella supuestamente trabajó hacia ese fin sin pausa, primero por su propia cuenta y después por medio de Iturbide, quien estaba locamente enamorado de la bella viuda. Pero el cómic no afirma que ella compartiera su pasión, sino que representa sus motivaciones como políticas más bien que personales. El texto concluye: "En esta dama maravillosa por su hermosura, su talento, su valentía y su temeridad vemos el albor de lo que en ese momento nacía para México: una sociedad nueva, criolla y mestiza, llena de contradicciones, pero viva y en pleno florecimiento". De modo que la presenta como un símbolo de la nación en su paso hacia el progreso, quien además

81 Bastien y Plaza, “La Güera Rodríguez”. 
fue una actora en la esfera pública tan importante como muchos hombres.

Esta visión de la Güera como actora política también resalta en una novela de 2005, El águila en la alcoba: la Güera Rodríguez en los tiempos de la independencia nacional, escrita por el abogado e historiador aficionado Adolfo Arrioja Vizcaíno. ${ }^{82}$ El texto demuestra cómo habían cambiado las actitudes hacia el poder femenino. Para los enemigos de Iturbide en el siglo XIX la sugerencia de que tomaba consejos de una mujer era seña de su debilidad. A principios del siglo xx, Romero de Terreros negó que su tatarabuela influyera en la política porque el poder femenino todavía se veía negativamente. Ya para mediados de siglo Valle-Arizpe muestra una actitud ambivalente hacia la participación femenina en la política. Y para el final de siglo esa participación se celebraba. Pero para principios del XXI no todos la usaban para fortalecer el nacionalismo. Al contrario, Arrioja Vizcaíno lamenta que el sexismo mexicano hubiera impedido que esta mujer sabia tomara las riendas del poder en vez de tener que operar desde la sombra. México habria tomado un camino diferente, escribe, "Si Iturbide hubiera sido la mujer y ella el hombre", porque se hubiera consolidado un gobierno estable. Pero los hombres con los que trabajaba no eran dignos de ella: el incompetente Hidalgo no pudo controlar a sus seguidores y el tonto vanidoso de Iturbide dejó que el poder se le subiera a la cabeza. En esta historia sin héroes, el autor usa la figura de "la mujer más notable de México" para criticar el patriarcado y expresar su profundo desengaño con el estado de su país.

Estas obras contribuyeron a una reevaluación del papel político de la Güera Rodríguez. Para fines del siglo xx muchos la consideraban como una de las principales heroínas mexicanas. Ya aparecía en los diccionarios biográficos, y en algunos textos llegaba a eclipsar a las hasta entonces reinantes Leona Vicario

82 Arrioja Vizcaíno, El águila en la alcoba, esp. pp. 339-342. 
y la Corregidora. Por ejemplo, la Enciclopedia de México de 1997, una colaboración de varios historiadores distinguidos, escogió a la Güera como la única heroína de la independencia incluida en los dos volúmenes de la obra. ${ }^{83}$ Y para el bicentenario de 2010 su presencia era ubicua. El contraste con su ausencia en las celebraciones del centenario en 1910 es asombroso. Tomó casi 200 años para que entrara al panteón de los héroes de México.

El ascenso de su reputación como heroína refleja el desarrollo de su leyenda a medida que sucesivos intérpretes jugaban con su historia. También refleja la reevaluación de la importancia de Iturbide: la Güera, como la mujer que supuestamente lo había guiado a liberar la nación, pasó a ser la Madre de la Patria. Su ascenso además refleja la obsesión contemporánea con la celebridad, la belleza y el erotismo, área en que las (supuestamente) adustas Corregidora y Vicario no podían competir. Por lo tanto, su creciente fama también se debe al sexismo mexicano, porque aún en el nuevo milenio, las mujeres poderosas, inteligentes e irreverentes suelen ser admiradas sobre todo si también son bellas, ultrafemeninas y simpáticas -y, pese a su prestigio como actor político, nunca se borró su identidad de femme fatale.

Otra clave de su persistente atractivo es el deseo universal de tener superhéroes que combatieran el mal. Como una Mujer Maravilla, la Güera -por lo menos según la leyenda-superó los prejuicios de su época, triunfó sobre su primer marido abusivo, venció a los poderosos inquisidores y tuvo un papel central en derrocar al régimen colonial. Claro que ninguna de estas representaciones concuerda con la vida de la "verdadera" María Ignacia Rodríguez. Pero en su camino a convertirse en ícono, se había apartado más y más de la mujer de carne y hueso que

83 Guedea, “Rodríguez de Velasco", t. II, p. 1286. La Güera ya aparecía en el Diccionario Porrúa (1964), pp. 1224-1225, y después en muchos otros diccionarios de ese tipo. 
vivió en los últimos años de la colonia y los primeros de la república.

La construcción de estos mitos demuestra cómo el pasado es constantemente reelaborado para adaptarlo al presente. Generaciones de mexicanos han interpretado -y reinventado- a la Güera Rodríguez de acuerdo con sus posiciones sobre el género, la política y la nación. Para algunos encarnaba la sexualidad y el escándalo, para otros era una mujer liberada y fuerte, o la víctima de un régimen patriarcal, o una importante figura en la creación del México moderno y una alegoría de la nación. Estas diversas visiones dan testimonio de su maleabilidad como símbolo. De hecho, su habilidad de cambiar con los tiempos la ha mantenido relevante porque los mitos tienen que ser constantemente renovados para seguir vigentes. ${ }^{84} \mathrm{Su}$ rica trayectoria en la memoria popular nos recuerda que la historia todavía vive y que las narraciones históricas merecen un escrutinio cuidadoso.

\section{SIGLAS Y REFERENCIAS}

AGN, IC, IV Archivo General de la Nación, fondo Instituciones Coloniales, Indiferente Virreinal, Ciudad de México, México.

AGN, IC, I Archivo General de la Nación, fondo Instituciones Coloniales, Inquisición, Ciudad de México, México.

AGN, IV, C Archivo General de la Nación, fondo Indiferente Virreinal, Criminal, Ciudad de México, México.

AGN, IV, M Archivo General de la Nación, fondo Indiferente Virreinal, Matrimonios, Ciudad de México, México.

AGN, RH, OV Archivo General de la Nación, fondo Real Hacienda, Oficios Vendibles, Ciudad de México, México.

AGN, VM Archivo General de la Nación, fondo Vínculos y Mayorazgos, Ciudad de México, México.

AHCM, AC Archivo Histórico de la Ciudad de México, fondo Ayuntamiento: Comisiones, 1728-1856, Ciudad de México, México.

AHN Archivo Histórico de Notarías de la Ciudad de México, Ciudad de México, México.

$\overline{84}$ Sobre este punto, véase Tuñón, “¿Pueden existir?”, p. 306. 
AP Archivo Parroquia de la Asunción, Sagrario Metropolitano Catedral de México, Ciudad de México, México.

FN Familias novohispanas: un sistema de redes, https:// gw.geneanet.org/sanchiz.

FS Family Search database, Church of the Latter Day Saints, fondo Mexican Church Records, http://www.FamilySearch.org/search.

FUNAM Filmoteca de la UNAM, Subdirección de Acervos, Ciudad de México, México.

Agüeros, Victoriano y Juan de Dios Peza (coords.), Episodios de la Guerra de Independencia, México, Instituto Nacional de Estudios Históricos de la Revolución Mexicana, 2008, ts. I y II.

Alamán, Lucas, Historia de México desde los primeros movimientos que prepararon su independencia en el año de 1808 hasta la época presente, 18491853; 5 vols., México, Imprenta de J. Mariano Lara, México, Publicaciones Herrerías, 1938, tt. I y V.

Alessio Robles, Vito, "Introducción bibliográfica: El Barón Alejandro de Humboldt, su vida y su obra”, en su edición de Alejandro de Humboldt, Ensayo político sobre el reino de la Nueva España, México, Pedro Robredo, 1941, t. I, pp. 9-121.

Amador, Elías, Noticias biográficas de insurgentes apodados, México, Secretaría de Educación Pública, 1946.

Arrioja Vizcaíno, Adolfo, El águila en la alcoba: la Güera Rodríguez en los tiempos de la independencia nacional, México, Grijalbo, 2005.

Arrom, Silvia M., La mujer mexicana ante el divorcio eclesiástico, 1800-1857, México, Secretaría de Educación Pública, SepSetentas, 1976.

Bastien, Rémy y Dolores Plaza, "La Güera Rodríguez: bella conspiradora mexicana”, en Hombres y Héroes, 158 (29 ago. 1990).

Beruete, Miguel de, Elevación y caída del emperador Iturbide, prólogo y notas de Andrés Henestrosa, México, Fondo Bruno Pagliai, 1974.

Blanco, José Joaquín, Álbum de pesadillas mexicanas: crónicas reales e imaginarias, México, Ediciones Era, 2002. 
Bustamante, Carlos María de, Cuadro histórico de la Revolución mexicana comenzada el 15 de septiembre de 1810 ..., México, Mariano Lara, 1843-1844, ts. I y II.

Bustamante, Carlos María de, Diario histórico de México, 1822-1848, editado por Josefina Vázquez y Héctor Cuauhtémoc Hernández Silva, México, Centro de Investigaciones y Estudios Superiores en Antropología Social, El Colegio de México, 2 CD, 2003.

Bustamante, Carlos María de, Suplemento a la historia de los tres siglos de México..., México, Testamentaria de D. Alejandro Valdés, 1836, t. IV.

Calderón de la Barca, Fanny, Life in Mexico: The Letters of Fanny Calderón de la Barca, with New Material from the Author's Private Journals, 1843, nueva edición de Howard T. Fisher y Marion Hall Fisher, Garden City NY, Doubleday, 1966.

Castillo Ledón, Luis, Hidalgo: la vida del héroe, México, Talleres Gráficos de la Nación, 1948, t. I.

Chust, Manuel y Víctor Mínguez (coords.), La construcción del héroe en España y México (1789-1847), Valencia, Universitat de València, 2003.

Curiel, Fernando, "Prólogo”, en Guillermo Prieto, Obras completas, México, Consejo Nacional para la Cultura y las Artes, 1992, pp. 15-47.

Diccionario Porrúa de historia, biografía y geografía de México, México, Porrúa, 1964.

Diccionario Porrúa de historia, biografía y geografía de México, México, Porrúa, 1995, 4 volúmenes.

Fernández de Lizardi, José Joaquín, Calendario para el año de 1825, dedicado a las señoritas americanas, especialmente a las patriotas, por el Pensador Mexicano, 1825, reimpreso como Heroinas mexicanas: María Leona Vicario, M. Rodríguez Lazarín, María Fermina Rivera, Manuela Herrera y otras, México, Biblioteca de Historiadores Mexicanos, 1955.

Fernández y Fernández, Aurora, Mujeres que bonran a la patria, México, Imprenta Zavala, 1958.

Fossey, Mathieu de, Le Mexique, París, Henri Plon, 1857. 
Galeana, Patricia, Museo de la mujer, México, Universidad Nacional Autónoma de México, 2012.

Garci, Antonio, Más pendejadas célebres en la historia de México, México, Diana, 2011.

García, Genaro (comp.), Documentos históricos mexicanos..., 1910, Nendeln, Liechtenstein, Kraus Reprint, 1971, t. V.

GuARDia, Sara Beatriz (coord.), Las mujeres en la Independencia de América Latina, Lima, Centro de Estudios de la Mujer en la Historia de América Latina, Universidad San Martín de Porres, unEsco, 2010.

Guedea, Virginia (comp.), Prontuario de los insurgentes, México, Universidad Nacional Autónoma de México, 1995.

GuedeA, Virginia, "Rodríguez de Velasco y Osorio Barba, María Ignacia (La Güera Rodríguez)", en Encyclopedia of Mexico: History, Society \& Culture, Michael Werner (coord.), Chicago, Fitzroy Dearborn, 1997, t. II, p. 1286.

Krumm-Heller, Arnoldo, "Esbozo biográfico del barón Alejandro von Humboldt", en Ernst WiтTісH et al., Memoria científica para la inanguración de la estatua de Alejandro de Humboldt obsequiada por S.M. el emperador alemán Guillermo II a la Nación Mexicana, con motivo del Primer Centenario de su Independencia, México, Müller Hermanos, 1910, pp. 1-42.

LADD, Doris M., The Mexican Nobility at Independence, 1780-1826, Austin, University of Texas Press, 1976.

Mandrell, James, Don Juan and the Point of Honor: Seduction, Patriarchal Society, and Literary Tradition, University Park, PA, Pennsylvania State University Press, 1992.

Martínez NúÑEz, César Alejandro, "Biografía crítica de la Güera Rodríguez, 1778-1851", tesis de licenciatura en historia, México, Universidad Nacional Autónoma de México, 2010.

Moreno JuÁrez, Sergio, "Presencia, participación y representación femenina en los dos Centenarios de la Independencia nacional (1910 y 1921)", en Signos Históricos, 14: 27 (ene.-jul. 2012), pp. 24-62.

Olmedillo, Carlos, "México, 1808-1821: algunas aportaciones históricas", en Historia Mexicana, Ix: 4 (36) (abr.-jun. 1960), pp. 586-600. 
Ortega y Medina, Juan, Humboldt desde México, México, Universidad Nacional Autónoma de México, 1960.

Pouwels, Joel Bollinger, Political Journalism by Mexican Women during the Age of Revolution, 1876-1940, Lewiston, Nueva York, Edwin Mellen Press, 2006.

Prieto, Guillermo, Memorias de mis tiempos (1828-1853), París-México, Vda. de C. Bouret, 1906, ts. I y II.

Rocafuerte, Vicente, Bosquejo ligerísimo de la Revolución de Mégico desde el grito de Iguala hasta la proclamación imperial de Iturbide, 1822; México, Porrúa, 1984.

Romero de Terreros y Vinent, Manuel, Los Condes de Regla: apuntes biográficos, México, Imp. y Fotograbado M. León Sánchez, 1909.

Romero de Terreros y Vinent, Manuel, Ex-Antiquis: Bocetos de la vida social en la Nueva España, Guadalajara, Jaime, 1919.

Romero de Terreros y Vinent, Manuel, La Corte de Agustín I, emperador de México, México, Museo Nacional de Arqueología, Historia y Etnología, 1921.

Rubio Siliceo, Luis, Mujeres célebres en la independencia de México, México, Talleres Gráficos de la Nación, 1929.

SÁnchez Robles, María Guadalupe, "La Güera Rodríguez, a doscientos años de la independencia de México", en Guardia (coord.), 2010, pp. 364-369.

SChroeder Inclán, Federico, Hoy invita la Güera: comedia anti-histórica en tres actos, en edición con Salvador Novo, La Culta Dama, México, Fondo de Cultura Económica, 1997, pp. 65-136.

Sosa, Francisco, Biografías de mexicanos distinguidos, México, Oficina Tipográfica de la Secretaría de Fomento, 1884.

Sosa, Octavio, Diccionario de la ópera mexicana, México, Instituto Nacional de Bellas Artes, Conaculta, 2005.

Tecuanhuey, Alicia, "La imagen de las heroínas mexicanas", en Chust y Mínguez (coords), 2003, pp. 71-90. 
Torrente, Mariano, Historia de la Revolución hispano-americana, Madrid, Imp. de Moreno, 1830, t. 3.

Torrente, Mariano, Historia de la Independencia de México, Madrid, Editorial América, 1918.

TuÑón, Julia, “¿Pueden existir las heroínas en celuloide? La representación de las mujeres insurgentes en el cine mexicano (1934-1991)", en GuARDIA (coord.), 2010, pp. 303-315.

Valle, Rafael Heliodoro del, Bolívar en México, México, Secretaría de Relaciones Exteriores, 1946.

Valle-Arizpe, Artemio de, La Güera Rodríguez, México, Porrúa, 1960.

VAlle-Arizpe, Artemio de, La Güera Rodríguez: relatos reales del sorprendente y divertido personaje de la historia de México, México, Lectorum, 2011.

Wright de Kleinhans, Laureana, Mujeres notables mexicanas, México, Tip. Económica, 1910.

Zárate Toscano, Verónica, Los nobles ante la muerte en México: actitudes, ceremonias y memoria (1750-1850), México, El Colegio de México, Instituto de Investigaciones Dr. José María Luis Mora, 2005.

Zorrilla, José, Don Juan Tenorio. Drama religioso-fantástico en dos partes, 1844; ed. y notas de Carolyn Lukens-Olson, Newark DEL, Cervantes \& Company, 2004. 